\title{
Bioactivity Enhanced Isolated Carpaine from Carica papaya Leaves for Platelet Stimulating Activity
}

\author{
V. S. TAMBE*, D. D. WAICHAL AND R. R. CHANSHETTY \\ Department of Quality Assurance Techniques, PES Modern College of Pharmacy (For Ladies), Moshi, Pune, Maharashtra \\ 412105, India
}

Tambe et al.: Bioactivity Enhanced Carpaine with Platelet Stimulating Activitys

\begin{abstract}
Carica papaya leaves are used in folklore medicine for the treatment of different types of thrombocytopenia associated with diseases and drugs. There are several scientific studies carried out on humans and animal models to confirm the efficacy of papaya leaves extract for the treatment of thrombocytopenia. In the present study, the alkaloid, carpaine extracted from papaya leaves was found to have platelet stimulating activity. Papaya leaves powder was extracted by microwave with a mixture of methanol: glacial acetic acid: water $(180: 2: 1.6 \mathrm{v} / \mathrm{v} / \mathrm{v})$. The extract was treated with suitable solvent to obtain alkaloid fraction. From the total alkaloids, carpaine was further separated by preparative thin layer chromatography, purified and analyzed. Carpaine was complexed with beta-cyclodextrin and mixed with piperine. The complex was administered in thrombocytopenia induced rats. The results showed that bioavailability enhanced carpaine exhibits potent activity of increasing platelet count.
\end{abstract}

Key words: Alkaloid, Carica papaya leaves, carpaine, platelet stimulating activity, thrombocytopenia

Carica papaya Linn. belonging to family Caricaceae has been used to treat the ailments like malaria, dengue and jaundice. It is used for anti-inflammatory, hypoglycemic, antifertility, abortifacient, hepatoprotective, wound healing, anti-malarial and immunomodulatory activity. Recently, its antihypertensive and antitumor activities have also been established ${ }^{[1]}$. Its young leaves are rich in flavonoids, alkaloids, phenolic compounds, cynogenetic compounds and carotenoids ${ }^{[2]}$. Leaves extracts from Carica papaya is generally used for patients with dengue fever. There are certain studies carried out to prove the use of Carica papaya leaves in thrombocytopenia ${ }^{[3-8]}$. The extract is available in the form of capsules, tablets and syrup. Although herbal medicines acceptance is increasing in global market, the concern is raised about its inconsistent composition. Hence, it is necessary to assess the activity of isolated phytoconstituents.

Carpaine (fig. 1) belongs to the class of macrolide analogues. It is one of the major alkaloid of papaya leaves which have been studied for its cardiovascular effects $^{[9,10]}$. It slows the heart rate in humans and thus reduces blood pressure. It is reported to have anthelmintic action, anti-plasmodial ${ }^{[11]}$ and anticancer activity $^{[1,12,13]}$. Carpaine is isolated and identified from

*Address for correspondence

E-mail: vrushalitambe99@gmail.com

July-August 2021
Carica papaya leaves with the content of $0.93 \mathrm{~g} / \mathrm{kg}^{[14]}$. The identification of carpaine as active compound for anti-plasmodial activity has been reported. It is also reported to increase platelet count in rats $^{[15]}$. In this study, an attempt was made to enhance carpaine extraction using microwave and to evaluate the antithrombocytopenic activity of Carica papaya leaves extract, carpaine and its available marketed formulation.

\section{MATERIALS AND METHODS}

\section{Reagents and chemicals:}

All solvents (analytical grade) were purchased from Loba Chemie, (India). Dragondraffs reagent and Silica gel $60 \mathrm{~F}_{254}$ plates were procured from Merck (Germany). Marketed tablet formulation containing $1100 \mathrm{mg}$ of Carica papaya leaves extract was purchased from local market.

This is an open access article distributed under the terms of the Creative Commons Attribution-NonCommercial-ShareAlike 3.0 License, which allows others to remix, tweak, and build upon the work non-commercially, as long as the author is credited and the new creations are licensed under the identical terms

Accepted 16 July 2021

Revised 11 September 2020

Received 03 February 2020 Indian J Pharm Sci 2021;83(4):723-731 


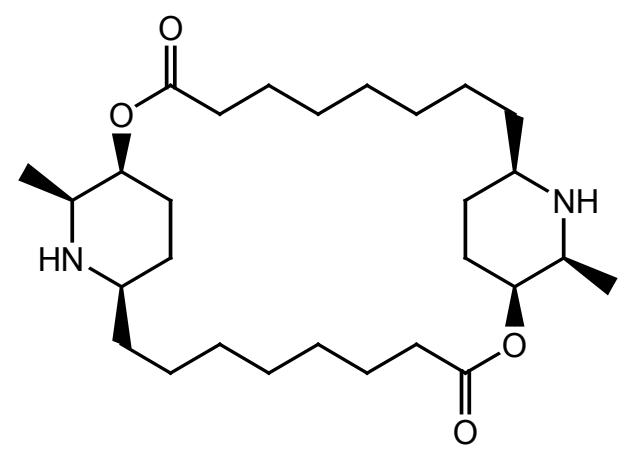

Fig. 1: Structure of carpaine

\section{Plant material:}

Matured healthy leaves of plant of Carica papaya were collected from local area of Jadhavwadi, Pune, India during the period of August-September 2015. The plant was taxonomically classified by the botanist Mrs. J. Jayanthi from the Botanical Survey of India, Pune and a voucher of 100-1/IDEN.CER./2018/73. Leaves were thoroughly washed with distilled water to remove dust. They were shed dried below $45^{\circ}$ for 5 $\mathrm{d}$. The leaves were cleaned by removing the stalk and woody part and grind to get fine powder. It was sieved and kept in air tight container at room temperature away from moisture for further study. It was analyzed for color, odor, taste, foreign matter, ash value, acid insoluble ash, water soluble ash and loss on drying.

\section{Extraction and isolation of carpaine:}

The powdered leaves were extracted using microwave assisted extraction (MAE) process and conventional extraction. $20 \mathrm{~g}$ of leaves powder was extracted with a mixture of methanol, glacial acetic acid and water $(180: 2: 1.6 \mathrm{v} / \mathrm{v} / \mathrm{v})$ in microwave extraction flask for 6 min at 140 watt $\left(70^{\circ}\right)$. For conventional extraction $20 \mathrm{~g}$ of leaves powder was extracted with a mixture of methanol, glacial acetic acid and water (180:2 $: 1.6 \mathrm{v} / \mathrm{v} / \mathrm{v}$ ) in soxhlet extractor for $17 \mathrm{~h}$ at $70^{\circ}$. Both extract were concentrated on electric water bath. It was tested for the presence of alkaloids, flavanoids, saponins, steroids and glycosides, etc.

The extract obtained by MAE ( $8.4 \mathrm{~g}$ ) was further washed with petroleum ether $((\mathrm{PE}), 160 \mathrm{ml})$ until $\mathrm{PE}$ layer was colourless. After removal of chlorophyll, the extract was basified with concentrated ammonia $(28 \%, 8 \mathrm{ml})$ followed by partitioning the extract in distilled water $(80 \mathrm{ml})$ and PE $(200 \mathrm{ml})$. The mixture was sonicated for $10 \mathrm{~min}$ and then was kept overnight without disturbance. On next day, the PE layer was collected and evaporated for removal of PE. The residue obtained was alkaloid fraction. Obtained alkaloid fraction was partitioned in n-hexane $(80 \mathrm{ml})$, sonicated for $5 \mathrm{~min}$ and kept aside for $1 \mathrm{~h}$. Hexane layer contained carpaine and its derivatives. Isolated fraction from hexane was separated using preparative thin layer chromatography (TLC) by using mobile phase toluene:ethyl acetate:glacial acetic acid $(5: 3.5: 1.5, \mathrm{v} / \mathrm{v} / \mathrm{v})$ to get pure carpaine.

\section{Spectroscopic identification of carpaine:}

Isolated fraction was scanned with double beam ultraviolet (UV) visible spectrophotometer in the range of 200-400 nm. High performance liquid chromatography-tandem mass spectrometry (HPLCMS/MS) study was performed for characterization of carpaine. The chromatographic system consisted of Agilent binary LC 1260 coupled to Agilent 6540 UHD Q-TOF mass spectrometer (National chemical laboratory (NCL), MS department, Pune). LC separation was performed on Neosphere $\mathrm{C}_{18}$ column $(250 \mathrm{~mm} \times 2.1 \mathrm{~mm}, 5.0 \mu \mathrm{m})$ with the mobile phase consisted of mixture of acetonitrile and water (90:10, v/v with addition of $0.1 \%$ formic acid), at a flow rate of $0.3 \mathrm{ml} / \mathrm{min}$. Run time was $10 \mathrm{~min}$. Data acquisition was carried out by analyst mass hunter work station software v. B. 05. 01. The mass spectrometer was operated in the positive ion mode. Ion spray voltage was $3500 \mathrm{~V}$ with the source temperature of $325^{\circ}$. Nitrogen was used as curtain, desolvation and nebulization gas at $30 \mathrm{psi}$. The method was validated for specificity. Fourier transform infrared spectroscopy (FT-IR) spectrum of carpaine in the form of potassium bromide $(\mathrm{KBr})$ pellet was recorded on Shimadzu model in the range of $4000-400 \mathrm{~cm}^{-1}$. The ${ }^{1} \mathrm{H}$ NMR spectra was recorded on Bruker Avance (300 MHz, Swizerland) spectrometer in deuterated methanol $\left(\mathrm{CD}_{3} \mathrm{OD}\right)$.

\section{Solubility study of carpaine:}

Saturation solubility of carpaine was determined in different solvents like distilled water, 0.1 N Hydrochloric acid $(\mathrm{HCl})$ and phosphate buffer of $\mathrm{pH}$ 7.2. An excess of carpaine $(1 \mathrm{mg})$ was added to conical flask containing $2.5 \mathrm{ml}$ of solvent and content were stirred for $24 \mathrm{~h}$, on rotary shaker. The mixture was then filtered through Whatman filter paper \#41. The solubility of carpaine was determined spectrophotometrically at $227.20 \mathrm{~nm}$.

Phase solubility studies were performed by the method reported by Higuchi and Connors (1965). Briefly, excess amount of carpaine (1 $\mathrm{mg}$ ) was added to $2.5 \mathrm{ml}$ distilled water containing various concentration 
of beta-cyclodextrin $(\beta-\mathrm{CD})$. The carpaine to $\beta$-CD molar ratio was $1: 1,1: 2,1: 4$. The suspension was vigorously shaken for $24 \mathrm{~h}$ on rotary shaker. After equilibrium, the samples were filtered through a Whatman filter paper (\#41). Carpaine concentration was determined spectrophotometrically at $227.20 \mathrm{~nm}$ using ultraviolet-visible (UV/Vis) double beam spectrophotometer. Concentration of carpaine was plotted against the concentration of $\beta-C D$ in milliMoles in distilled water. The data was treated and the stability constant was calculated by using formula,

$\mathrm{Ks}=$ Slope/So (1-Slope)

Where Ks is the stability constant and So is solubility of carpaine in water.

Phase solubility constants in distilled water and phase solubility relationship were obtained.

\section{Preparation and evaluation of complexes:}

Carpaine and $\beta-C D$ complexes were prepared in the ratios $1: 1,1: 2$ and $1: 4$ by solvent evaporation method. An aqueous solution of $\beta-C D$ was added to a methanolic solution of carpaine. The resulting mixture was triturated for $45 \mathrm{~min}$ in motor and evaporated at $45-50^{\circ}$ in hot air oven until nearly dried. The mixture was sieved through sieve number (\#100).

Dissolution studies were conducted by weighing complex equivalent to $50 \mathrm{mg}$ of carpaine, using a United States Pharmacopeia (USP) II basket method (50 rpm, $37^{\circ}$ and $900 \mathrm{ml} 0.1 \mathrm{~N} \mathrm{HCl}, 120 \mathrm{~min}$ ) with a TDT-06T dissolution tester (Electrolab Pvt. Ltd, India). The results were compared with plain carpaine. The drug concentration was determined spectrophotometrically at $227.20 \mathrm{~nm}$ using UV-Vis double beam spectrophotometer (Shimadzu, UV-1800).

\section{Platelet stimulating activity:}

Male Wister rats weighing 200-250 g were obtained from the animal house facility of Laxmi biofarms Pvt. Ltd., Alephata, Pune 421411. Animal housing and handling were performed in accordance with Good Laboratory Practices (GLP) mentioned in Committee for the purpose of control and supervision of experiments on animal (CPCSEA) guidelines. The animal house is registered with the CPCSEA with registration no. 1036/ PO/Re/S/2007/CPCSEA, dated 18 April 2018. All experimental protocols were reviewed and approved by the institutional animal ethics committee prior to initiation of the experiment. The animals were housed in polypropylene cages and placed in the experimental room where they were allowed to acclimatize for a week before experiment. A $10 \%$ air exhaust conditioning unit was maintained along with a relative humidity of $55 \pm 5 \%$ and a temperature of $25 \pm 2^{\circ}$ in the animal house facility. A 12:12 light:dark cycle was also regulated for the experimental animals. The animals were fed on a commercially available rodent chow diet (Nutrivet sciences, Manikbaugh, Singhgad road, Pune) and tap water was provided ad libitum to the experimental animals.

Animals were randomly distributed in 6 groups $(n=4)$ viz. normal group, disease control group and 4 tests groups for screening the activity of different preparations. Thrombocytopenia was induced by busulfan at a dose of $10 \mathrm{mg} / \mathrm{kg}$ in Wister rats on a d 1 and 4 orally. The animals were treated with the test preparation for a period of $7 \mathrm{~d}$ which starts on the same day as that of busulfan dosing. The group 3, 4, 5, 6 were dosed with carpaine ( $4 \mathrm{mg} / \mathrm{kg}$ ), carpaine: $\beta$-CD complex $(4: 8 \mathrm{mg} / \mathrm{kg})$, carpaine: $\beta-\mathrm{CD}$ :piperine $(4: 8: 15 \mathrm{mg} / \mathrm{kg})$ and marketed formulation $(200 \mathrm{mg} / \mathrm{kg}$ ) respectively based on acute toxicity study. All the test preparations were administered as a suspension in $1 \mathrm{ml}$ distilled water, orally. Platelet counts were determined on $d$ 1 prior to the initiation of dosing of either test preparation or busulfan and on $7^{\text {th }} \mathrm{d}$ in an automated hematology analyzer VetScan HM-5. Values are expressed as mean \pm standard error of mean (SEM) and data were analyzed using one way analysis of variance (ANOVA) followed by the Dunnett's multiple comparison test at $\mathrm{p}<0.05$, using Graphpad InStat (version 3).

\section{RESULTS AND DISCUSSION}

The crude drug powder was observed to be dark green in color. Determination of ash value is helpful in determining the quality and purity of crude drugs, especially in powder form. The total ash value was found to be $3.6 \%$ which was found to be in the normal range of 3.45-5.35 as per Indian Pharmacopoeia. The loss on drying was found to be $6.75 \% \mathrm{w} / \mathrm{w}$ (Normal range: 6.05-11.95). The values of foreign matter, acid insoluble ash and water soluble ash were found to be $4.21,1,2.22 \% \mathrm{w} / \mathrm{w}$ respectively.

Preparation of extract and isolation of carpaine was shown here. MAE is preferred method due to higher yield with less solvents and time requirement. The amount of isolated alkaloid was found to be $0.0122 \mathrm{~g}$. The percentage (\%) yield of extract by 
MAE was found to be $42 \%$ as compared to $31 \%$ by conventional soxhlet extraction.

Phytochemical screening of crude methanolic extract was carried out. The extract of Carica papaya leaves was tested for the presence of various phytoconstituents. It showed the presence of alkaloids, flavonoids, tannins, glycosides, proteins and amino acids. TLC showed presence of alkaloids in crude methanolic extract with Dragendorff's reagent. Alkaloid fraction showed two different spots with chloroform:methanol $(8.5: 1.5 \mathrm{v} / \mathrm{v})$ as a mobile phase. This mobile phase was used for separation and isolation of alkaloids using preparative TLC.

The UV spectra of alkaloid showed characteristics peak at $227.20 \mathrm{~nm}$ in methanol. The purity of the isolated material was determined by high performance liquid chromatography (HPLC) analysis according to the area normalization method and was calculated to be $98.2 \%$. Retention time of alkaloid was found to $2.40 \mathrm{~min}$. Alkaloid was characterized further by infrared spectroscopy (IR), nuclear magnetic resonance (NMR) and mass spectrometry. The IR spectra showed the presence N-Hs $\left(3385 \mathrm{~cm}^{-1}\right)$, C-Hs (2956, 2950, 2918, $\left.2727 \mathrm{~cm}^{-1}\right), \mathrm{C}-\mathrm{Hb}\left(1383 \mathrm{~cm}^{-1}\right)$ and C-Os $\left(1020 \mathrm{~cm}^{-1}\right)$ functional groups. As compound contain carbonyl group, it is possible to have keto-enol tautomerism. The presence of band at $3760-3000 \mathrm{~cm}^{-1}$ is attributed to presence of $-\mathrm{OH}$ group. ${ }^{1} \mathrm{H}-\mathrm{NMR}$ spectra of isolated alkaloid showed the signal at $0.896(6 \mathrm{H}) \mathrm{d}$, 1.1-1.383 $(24 \mathrm{H})$ multiplet, $1.724(10 \mathrm{H})$ cyclic protons, $2.0(2 \mathrm{H})-\mathrm{CHN}, 2.415-2.459(4 \mathrm{H},+)-\mathrm{COCH}_{2}, 2.981$ $(2 \mathrm{H})-\mathrm{COH}, 4.9$ or $3.3(2 \mathrm{H})-\mathrm{NH}$ which confirm the structure of carpaine. The data was compared with the chemical shift values from the spectral library and were found to be same confirming the structure of isolated compound as carpaine.
Liquid chromatography-mass spectrometry (LC-MS) profile of isolated alkaloid has shown one major peak representing carpaine in the isolated fraction. Fig. 2 show LC-MS spectra of carpaine (positive ion mode; $\mathrm{m} / \mathrm{z} 479.88[\mathrm{M}+\mathrm{H}]^{+}$. As the compound has amino functional group, ionization efficiency was found to be better, in positive ionization mode. It indicates the presence of even number of nitrogen atoms in chemical structure. To confirm the structure further, liquid chromatography with tandem mass spectrometry (LCMS/MS) spectra (fig. 3) was acquired using Agilent 6540 UHD QTOF MS. The selected $479.88 \mathrm{~m} / \mathrm{z}$ was further fragmented. The observed fragments with their structures and error in mass calculation are shown in fig. 4 and Table 1.

Solubility study of isolated alkaloid is carried out. Carpaine was found to be practically insoluble in water $(48.12 \mu \mathrm{g} / \mathrm{ml})$. The solubility in aqueous systems having different $\mathrm{pH}$ showed $\mathrm{pH}$ dependent solubility. It was found to be more soluble in acidic $\mathrm{pH}$ $(35.12 \mu \mathrm{g} / \mathrm{ml})$ as compared to alkaline $\mathrm{pH}(18.55$ $\mu \mathrm{g} / \mathrm{ml})$.

Solubility enhancement of carpaine is discussed below. The calibration curve of carpaine (fig. 5) in distilled water and $0.1 \mathrm{~N} \mathrm{HCl}$ was found to be linear in the concentration range of $10-80 \mu \mathrm{g} / \mathrm{ml}\left(\mathrm{r}^{2}>0.995\right)$. In order to enhance the solubility of carpaine, it was complexed with $\beta-C D$. The phase solubility study of carpaine with $\beta$-CD was carried out in distilled water (Table 2). With increase in the concentration of $\beta-C D$, solubility of carpaine was found to increase. The carpaine could have complexed with the $\beta-\mathrm{CD}$ by formation of hydrogen bonding between its electronegative elements like nitrogen, oxygen and hydroxyl group of $\beta-C D$. The phase solubility constant $\left(\mathrm{K}_{\mathrm{st}}\right)$ in distilled water

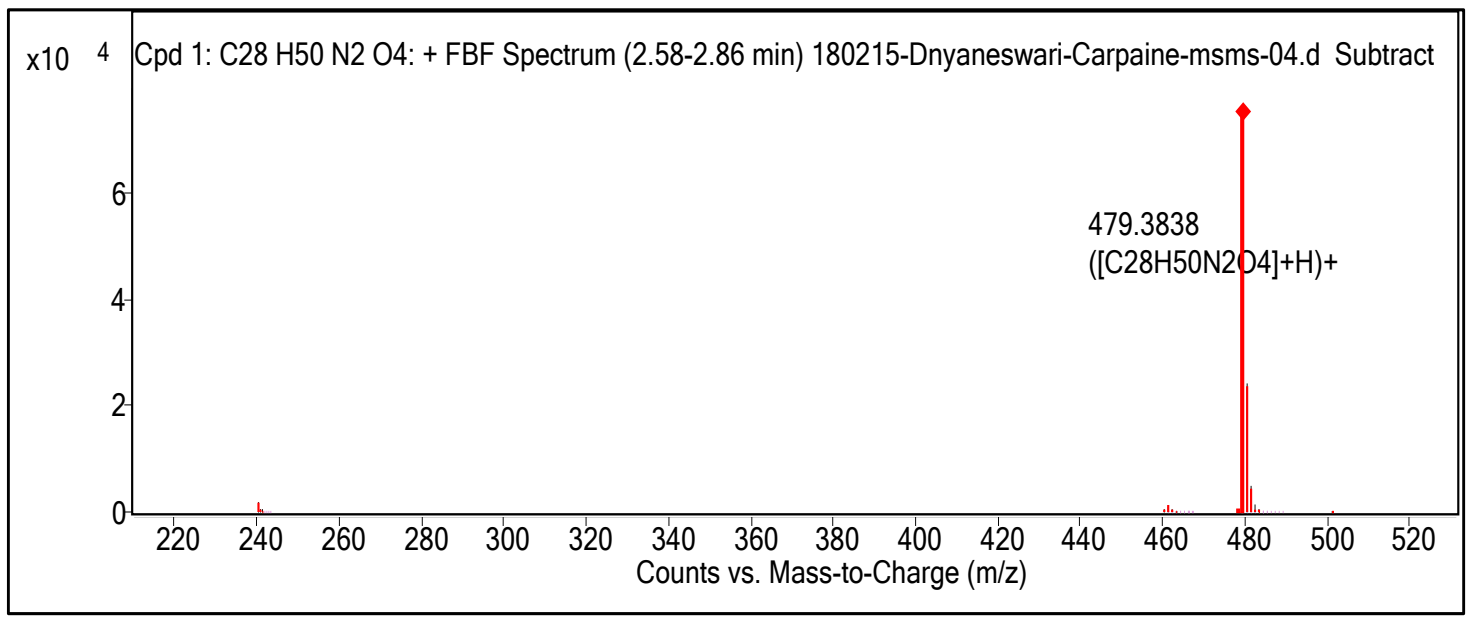

Fig. 2: LC-MS spectra of alkaloid 


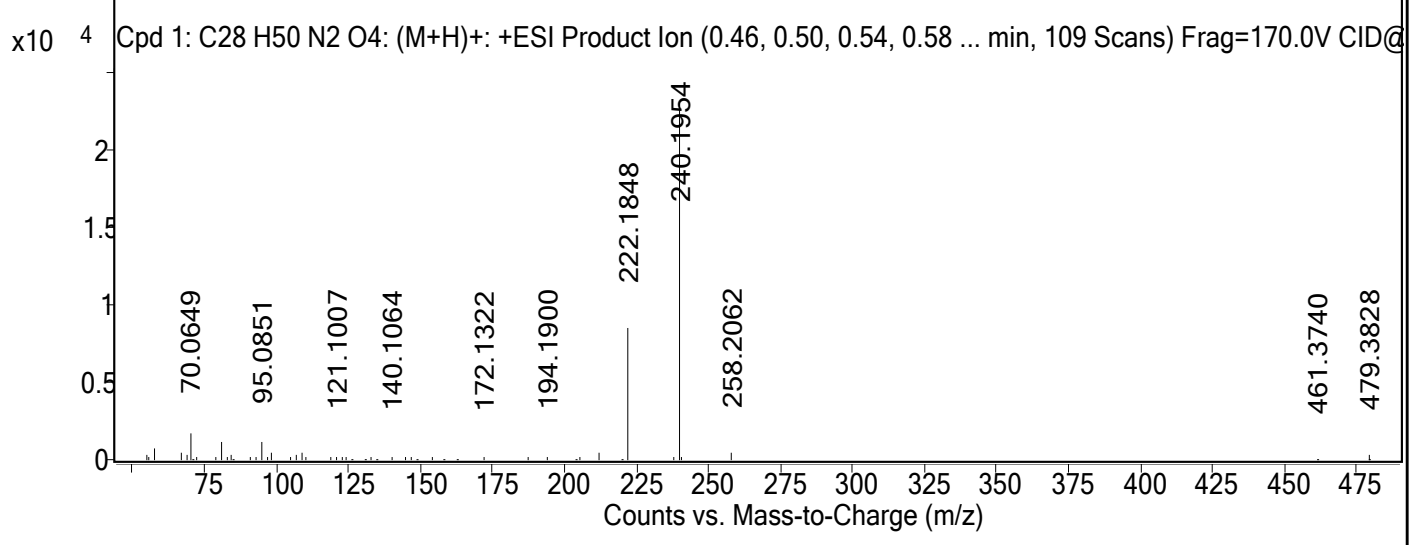

Fig. 3: LC-MS/MS spectra of isolated alkaloid
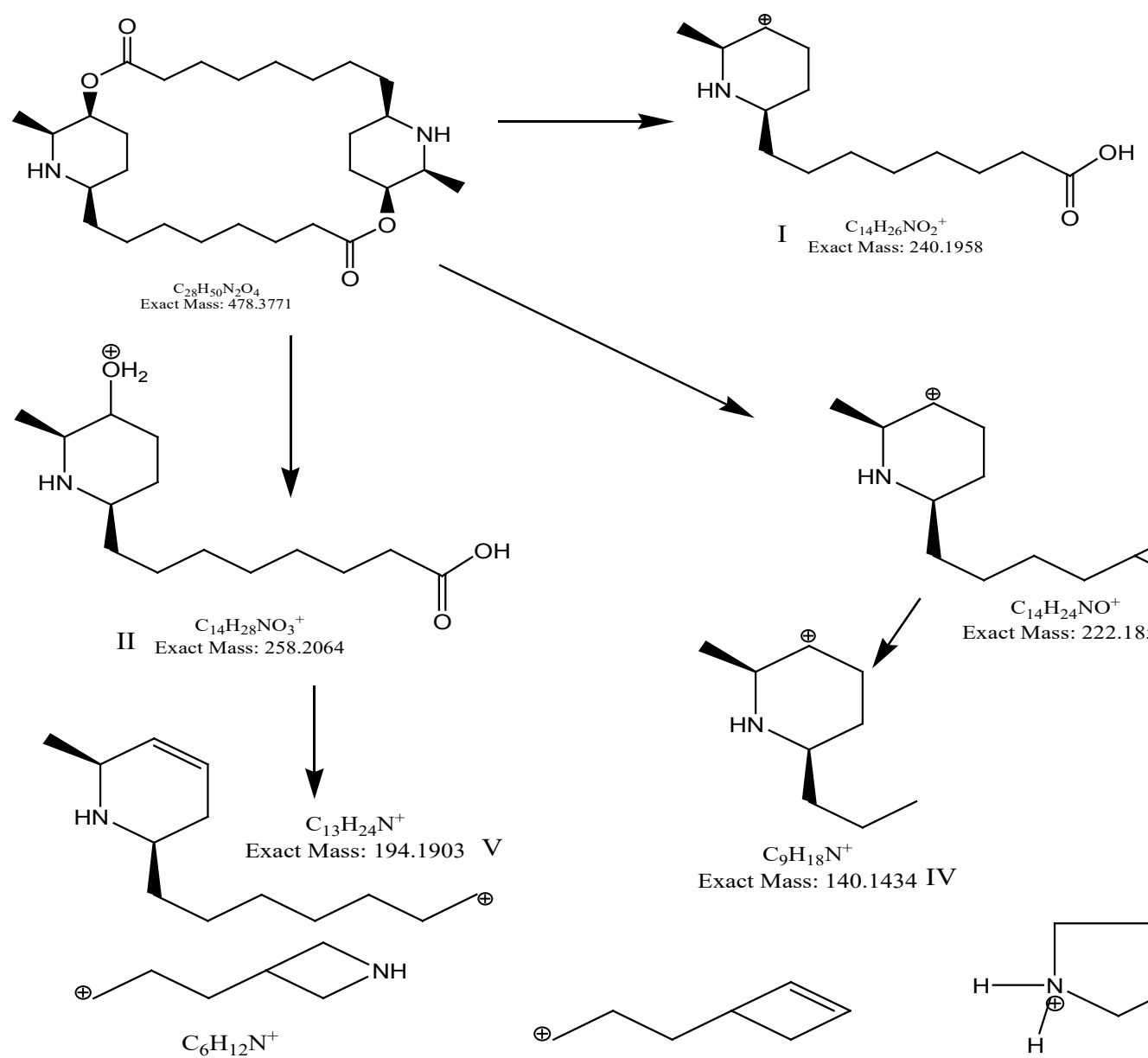

VI Exact Mass: 98.0964<smiles>OC1CC[C+]NC1</smiles>

$\mathrm{C}_{5} \mathrm{H}_{8} \mathrm{NO} \cdot \bullet+$

XI Exact Mass: 98.06

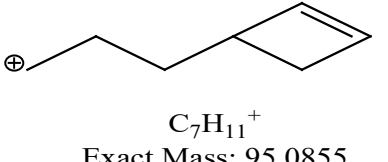

Exact Mass: 95.0855

VII

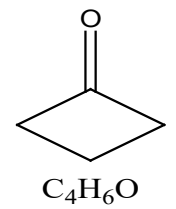

Exact Mass: 70.0419

$\mathrm{X}$

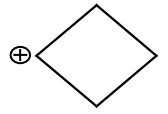

$\mathrm{C}_{4} \mathrm{H}_{7}{ }^{+}$

$\mathrm{X}$<smiles>C1CC[NH2+]C1</smiles>

$\mathrm{C}_{4} \mathrm{H}_{8} \mathrm{~N}^{*+}$

Exact Mass: 70.0651

Exact Mass: 55.0542
VIII

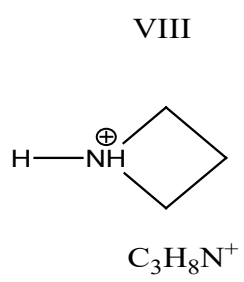

Exact Mass: 58.0651

XII

Fig. 4: Proposed fragmentation pattern of carpaine 
TABLE 1: OBSERVED FRAGMENTS

\begin{tabular}{lcccc}
\hline Fragment No. & Formula & Exact mass & Observed mass & Mass error (amu) \\
\hline $\mathrm{I}$ & $\mathrm{C}_{14} \mathrm{H}_{22} \mathrm{NO}_{2}^{+}$ & 240.1955 & 240.1958 & 1.2489 \\
II & $\mathrm{C}_{14} \mathrm{H}_{28} \mathrm{NO}_{3}^{+}$ & 258.2062 & 258.2064 & 1.24 \\
III & $\mathrm{C}_{14} \mathrm{H}_{24} \mathrm{NO}^{+}$ & 222.1848 & 222.1852 & 1.8003 \\
IV & $\mathrm{C}_{9} \mathrm{H}_{18} \mathrm{~N}^{+}$ & 140.1068 & 140.1434 & 261.229 \\
V & $\mathrm{C}_{13} \mathrm{H}_{24} \mathrm{~N}^{+}$ & 194.1902 & 194.1903 & 0.5149 \\
VI & $\mathrm{C}_{6} \mathrm{H}_{12} \mathrm{~N}^{+}$ & 98.0964 & 98.0964 & 0.000 \\
VII & $\mathrm{C}_{7} \mathrm{H}_{11}^{+}$ & 95.0851 & 95.0855 & 1.54. \\
VIII & $\mathrm{C}_{4} \mathrm{H}_{8} \mathrm{~N}^{+}$ & 70.0649 & 70.0651 & 2.8544 \\
IX & $\mathrm{C}_{5} \mathrm{H}_{8} \mathrm{NO}^{+\cdots}$ & 98.0962 & 98.06 & -369.0255 \\
X & $\mathrm{C}_{4} \mathrm{H}_{6} \mathrm{O}$ & 70.0649 & 70.0419 & -328.26 \\
XI & $\mathrm{C}_{4} \mathrm{H}_{7}^{+}$ & 55.04 & 55.0542 & 257.99 \\
XII & $\mathrm{C}_{3} \mathrm{H}_{8} \mathrm{~N}^{+}$ & 58.0649 & 58.0651 & 3.4444 \\
\hline
\end{tabular}

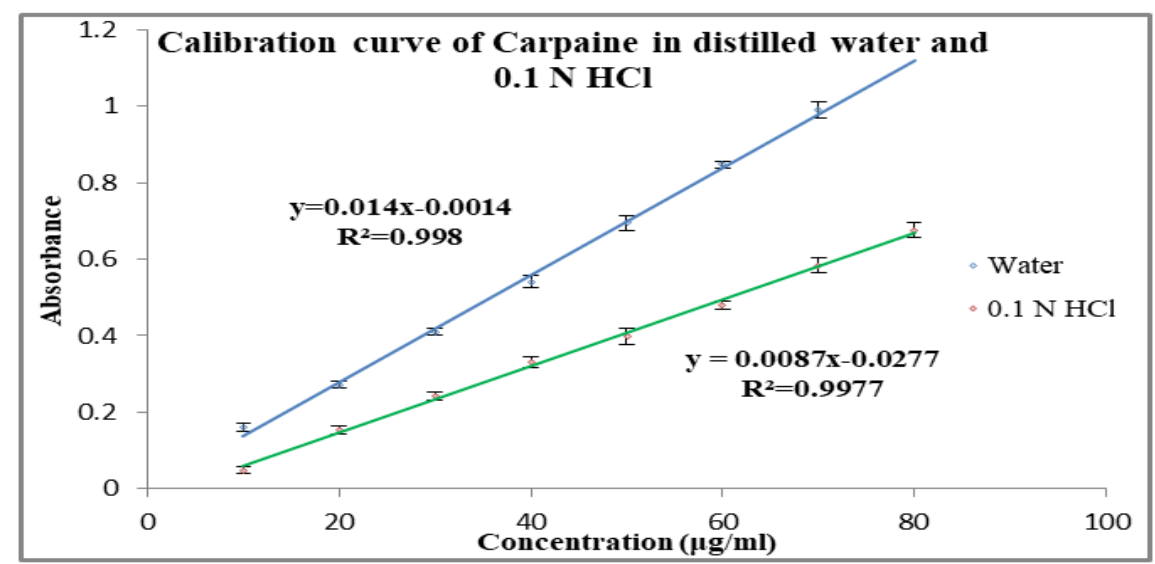

Fig. 5: Calibration curves of carpaine in distilled water and $0.1 \mathrm{~N} \mathrm{HCl}$

TABLE 2: PHASE SOLUBILITY DATA OF CARPAINE$\beta$-CD IN DISTILLED WATER

\begin{tabular}{lc}
\hline $\begin{array}{l}\text { Concentration of B-CD } \\
\text { (mol/l) }\end{array}$ & $\begin{array}{c}\text { Concentration of carpaine in } \\
\text { water (mol/l) }\end{array}$ \\
\hline 0.00000 & 0.0001021 \\
0.000352 & 0.000131 \\
0.000704 & 0.000162 \\
0.001409 & 0.002587 \\
\hline
\end{tabular}

was found to be 909.388 . The stability constant was in the ideal range of 100-5000. Solubility was found to increase approximately by 1.58 folds. The in vitro dissolution study was performed in $0.1 \mathrm{~N} \mathrm{HCl}$ for $1: 1$, $1: 2$ and $1: 4$ carpaine: $\beta$-CD complex. The study revealed that the $\beta$-CD showed enhancement in solubility for poorly water soluble carpaine. It showed enhancement in dissolution rate for $1: 1$ and $1: 2$ carpaine: $\beta-C D$ complex as compared to plain carpaine. In case of 1:4 carpaine: $\beta-C D$ complex, slight improvement in dissolution rate as that of plain carpaine was observed. But, it is less as compared to $1: 2$ and $1: 1$ carpaine: $\beta$ $\mathrm{CD}$ complex. Considering highest dissolution rate of 1:2 ratio, it was used for the further studies. The comparative dissolution profile of 1:2 complex and plain drug is given in fig. 6. From this, it was observed that the complex prepared using $\beta$-CD has improved percentage $(\%)$ of drug release. The time required for maximum release in $0.1 \mathrm{~N} \mathrm{HCl}$ was $30 \mathrm{~min}$.

Initially acute toxicity study was carried out. Oral administration of carpaine did not produce any toxic effects in rats. Carpaine was found to be safe and no mortality was observed up to the dose of $4 \mathrm{mg} / \mathrm{kg}$.

In vivo evaluation of platelet stimulating activity is carried out. Fig. 7 shows graphical presentation of platelet count. Results are expressed as mean \pm SEM. Comparison between the groups was made by one way ANOVA followed by Dunnett's multiple comparison test $(\mathrm{p}<0.05)$.

After thrombocytopenia induction by using busulfan (10 mg/kg body weight (BW), orally), platelet count was found to be decrease significantly (Table 3). This effect was attenuated by treatment with the test samples. On the $7^{\text {th }} \mathrm{d}$, the platelet count of disease control animals was dropped to a mean value of $101000 / \mu 1$ whereas the mean platelet count for the group receiving carpaine, $\beta-\mathrm{CD}$ and piperine was found 


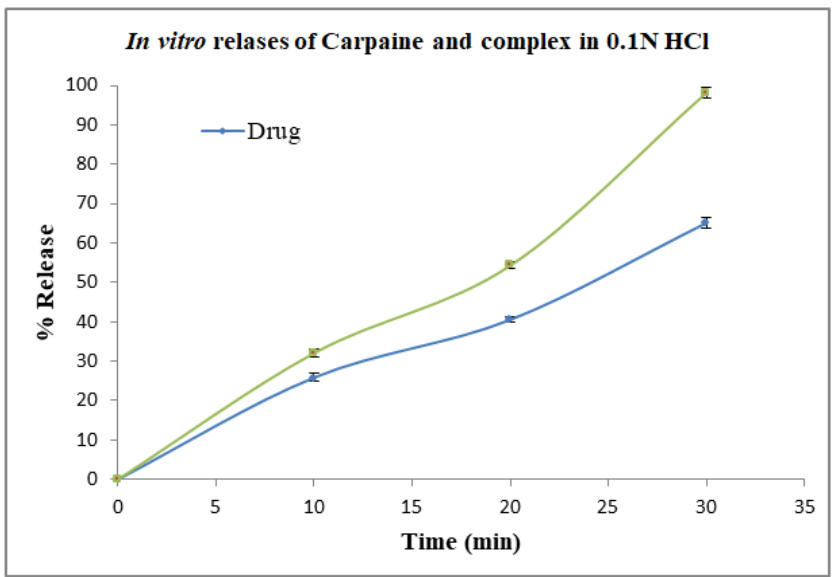

Fig. 6: In vitro release of carpaine and carpaine: $\beta-C D(1: 2)$ complex in $0.1 \mathrm{~N} \mathrm{HCl}$

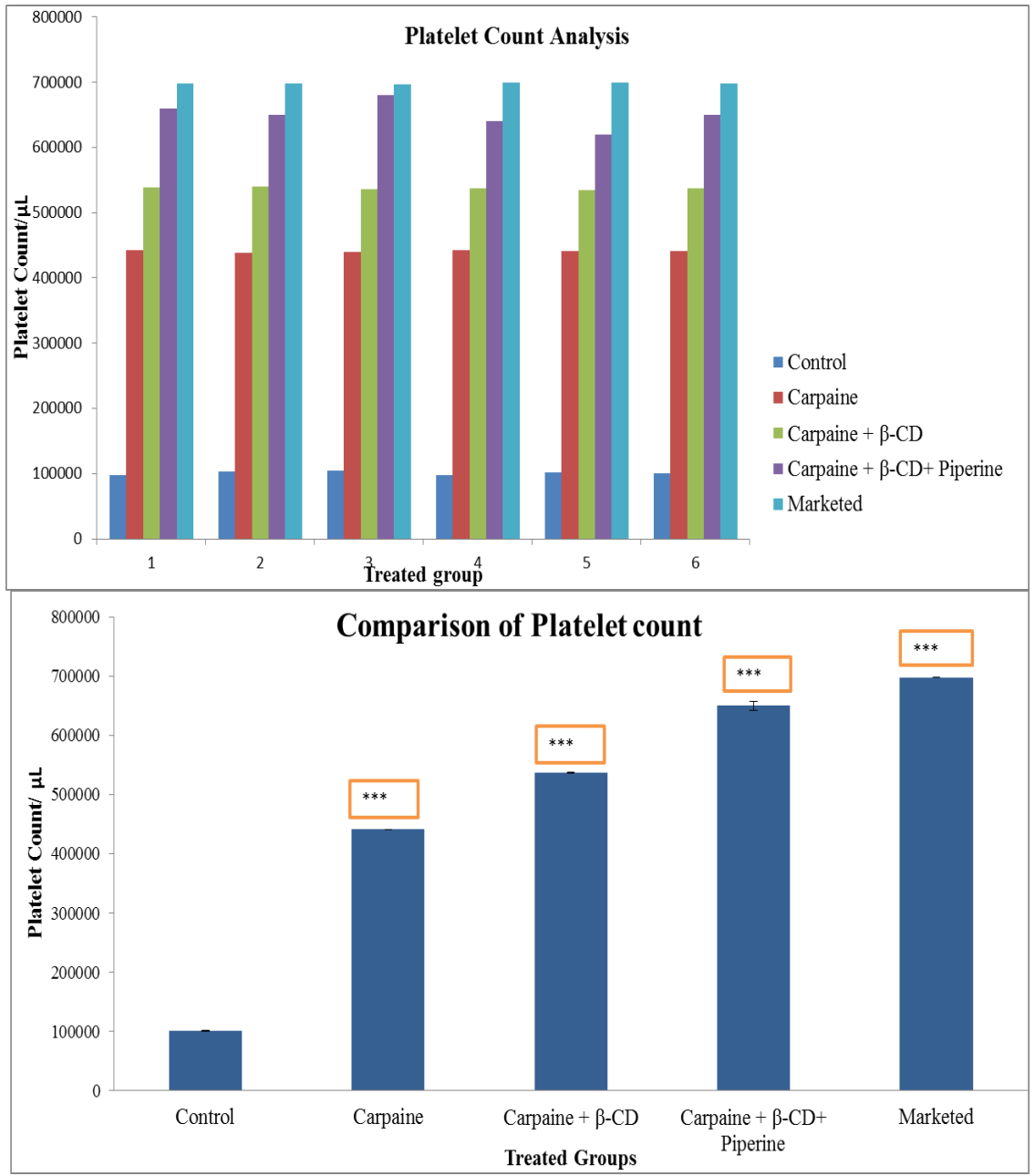

Fig. 7: Graphical presentation of platelet count analysis (ANOVA followed by Dunnett's multiple comparison test at $p<0.05$, $* * *$ indicates highly significant activity in comparison to control)

to be $650000 / \mu 1$. Carpaine was found to have significant platelet stimulating activity. Among all test samples, the platelet stimulating effect of mixture of carpaine, $\beta-\mathrm{CD}$ and piperine was found to be significant than plain carpaine and its $\beta$-CD complex. $\beta$-CD enhances the solubility of carpaine and piperine enhances the permeability of carpaine by increasing the absorption of drug in the gastrointestinal tract (GIT), increasing GIT vasculature by vasodilation to increase absorption of drugs, modulation of the cell membrane dynamic to increase transport of drugs across cell membranes or inhibit enzymes responsible for drug metabolism, especially in the liver when the drug passes through the liver after absorption from GIT. The difference 


\begin{tabular}{lcccc}
\hline & \multicolumn{4}{c}{ Groups } \\
\cline { 2 - 5 } Groups & $\begin{array}{c}\text { Before } \\
\text { thrombocytopenia } \\
\text { induction }\end{array}$ & $\begin{array}{c}\text { After } \\
\text { thrombocytopenia } \\
\text { induction }\end{array}$ & $\begin{array}{c}\text { After treatment } \\
\mathbf{2 4 ~ h}\end{array}$ & 7 d \\
\hline Normal group & $588000 \pm 0.451$ & $587000 \pm 1.208$ & $587000 \pm 0.987$ & $590000 \pm 0.672$ \\
Control group & $628000 \pm 1.34$ & $598000 \pm 2.123$ & $540000 \pm 1.671$ & $101000 \pm 0.890$ \\
Treated with carpaine & $512000 \pm 0.786$ & $410000 \pm 1.233$ & $416000 \pm 0.784$ & $441000^{* * *} \pm 2.341$ \\
Treated with carpaine+B-CD & $603000 \pm 2.08$ & $511000 \pm 0.945$ & $515000 \pm 1.36$ & $537000^{* * *} \pm 0.963$ \\
Treated with carpaine+B-CD+piperine & $502000 \pm 2.345$ & $446000 \pm 0.877$ & $547000 \pm 0.956$ & $650000^{* * *} \pm 1.324$ \\
Treated with marketed formulation & $610000 \pm 0.945$ & $586000 \pm 2.567$ & $615000 \pm 1.452$ & $698000^{* * *} \pm 1.845$ \\
\hline Note: & &
\end{tabular}

Note: ${ }^{* * *}$ indicates highly significant activity in comparison to control group

in the activity of marketed group and carpaine, $\beta-\mathrm{CD}$ and piperine mixture was found not to be significant. The platelet count was increased after inducing thrombocytopenia in both the groups. However, mechanistic study needs to be done to identify targets for this activity. Similarly, the plant also contains other alkaloids like pseudocarpaine-I, pseudocarpaine-II and choline. Research should be undertaken to determine their effect on platelet count. Carpaine has a macrocyclic dilactone structure. There is a need of better solubility enhancement strategies using different excipients and techniques taking in to consideration cyclic structure of carpaine.

Carica papaya has recently attracted attention due to its usefulness in the management of dengue. Hence, the study was focused on isolation, characterization and determination of platelet stimulating activity of alkaloids from Carica papaya leaves. MAE procedure for carpaine was optimized. Alkaloid was purified using preparative TLC. LC-MS study of isolated fraction was identified and confirmed to be carpaine with massto-charge ratio $(\mathrm{m} / \mathrm{z})$ 479.88. Further fragmentation study of carpaine was performed by LC-MS/MS. The IR spectra of isolated alkaloid have shown various absorption peaks corresponding to the structure of carpaine. From IR and NMR study, it was confirmed that the isolated compound was carpaine. It has $\mathrm{pH}$ dependent solubility. Antithrombocytopenic property of Carica papaya leaves is attributed to carpaine. Investigation of the effect of other alkaloids on platelet should be performed. No visible toxicity or any adverse effect was observed in animals treated with carpaine at a dose of $4 \mathrm{mg} / \mathrm{kg}$ for $8 \mathrm{~d}$. The platelet stimulating activity of carpaine, $\beta-\mathrm{CD}$ and piperine complex was comparable with the marketed formulation.

\section{Acknowledgements:}

The authors are thankful to PES Modern College of Pharmacy (For Ladies), Moshi, Pune for providing all the necessary facilities required for the research work.

\section{Ethical approval:}

All animal procedures were approved by Institutional Animal Ethics Committee at the Modern College of Pharmacy (for Ladies), Savitribai Phule Pune University (India).

\section{Conflict of interests:}

The authors declared no conflict of interest.

\section{REFERENCES}

1. Aravind G, Bhowmik D, Duraivel S, Harish G. Traditional and medicinal uses of Carica papaya. J Med Plants Stud 2013;1(1):7-15.

2. Yogiraj V, Goyal PK, Chauhan CS, Goyal A, Vyas B. Carica papaya Linn: an overview. Int J Herb Med 2014;2(5):1-8.

3. Chong ST, Prabhakaran R, Lee HK. An improved technique of propagating 'Eksotika' papaya. In: Chomchalow N, Chantrasmi V, Sukhvibul N, editors. ISHS Acta Horticulturae 787: International workshop on tropical and subtropical fruits. $1^{\text {st }}$ ed. Chiang Mai: Thailand; 2008.

4. Burdick EM. Carpaine: An alkaloid of Carica papaya: Its chemistry and pharmacology. Econ Bot 1971:363-5.

5. Hornick CA, Sanders LI, Lin YC. Effect of carpaine, a papaya alkaloid, on the circulatory function in the rat. Res Commun Chem Pathol Pharmacol 1978;22(2):277-89.

6. Brass L. Understanding and evaluating platelet function. Hematol Am Soc Hematol Educ Program 2010;2010(1):38796.

7. Gauer R, Braun MM. Thrombocytopenia. Am Fam Physician 2012;85(6):612-22.

8. McMillan R. Therapy for adults with refractory chronic immune thrombocytopenic purpura. Ann Intern Med 1997;126(4):307-14.

9. Vien DT, Loc TV. Extraction and quantification of carpaine from Carica papaya leaves of Vietnam. Int J Agric Environ Biotechnol 2017;2(5):2394-7.

10. Julianti T. Discovery of natural antiprotozoals from medicinal plants Saussurea costus and Carica papaya (Doctoral dissertation, University of Basel), Switzerland; 2014:41-8.

11. Julianti T, Oufir M, Hamburger M. Quantification of the antiplasmodial alkaloid carpaine in papaya (Carica papaya) leaves. Planta Med 2014;80(13):1138-42.

12. Wang $\mathrm{X}, \mathrm{Hu} \mathrm{C}, \mathrm{Ai} \mathrm{Q}$, Chen $\mathrm{Y}$, Wang Z, Ou S. Isolation and 
identification carpaine in Carica papaya L. leaf by HPLC-UV method. Int J Food Prop 2015;18(7):1505-12.

13. Otsuki N, Dang NH, Kumagai E, Kondo A, Iwata S, Morimoto C. Aqueous extract of Carica papaya leaves exhibits anti-tumor activity and immunomodulatory effects. J Ethnopharmacol 2010;127(3):760-7.

14. Julianti T, De Mieri M, Zimmermann S, Ebrahimi SN, Kaiser $\mathrm{M}$, Neuburger M, et al. HPLC-based activity profiling for antiplasmodial compounds in the traditional Indonesian medicinal plant Carica papaya L. J Ethnopharmacol 2014;155(1):426-34.

15. Zunjar V, Dash RP, Jivrajani M, Trivedi B, Nivsarkar M. Antithrombocytopenic activity of carpaine and alkaloidal extract of Carica papaya Linn. leaves in busulfan induced thrombocytopenic Wistar rats. J Ethnopharmacol 2016;181 $: 20-5$. 